\title{
Sensible Heat Fluxes over an Urban Area-Vancouver, B.C.
}

\author{
D. YAP' AND T. R. OKE ${ }^{2}$ \\ (Manuscript received 27 November 1973, in revised form 24 July 1974)
}

\begin{abstract}
The use of the eddy correlation technique is demonstrated for the measurement of sensible heat transfer in an urban area. The problems of time and space sampling (in the horizontal and vertical) are investigated. Based on 27 summer days of observations from a roof-top site in the central built-up part of Vancouver, the diurnal variation of sensible heat transfer above an urban area is described. The flux of heat at 1.2, 4 and $20 \mathrm{~m}$ above roof level largely reflected time and magnitude changes in the net radiation field. While being in phase with net radiation, the sensible heat flow commonly exhibited unusually high values in the late afternoon. Nocturnal urban sensible heat flow was quite unlike the normal rural pattern, often being directed into the atmosphere, Also at night the existence of flux divergence is suggested.
\end{abstract}

\section{Introduction}

It is often stated that the process of urbanization leads to marked changes in the surface energy balance of a city compared to its rural environs. Apart from a few studies on the radiation fluxes, however, there is little solid experimental evidence relating to urban energetic exchanges. In particular, the turbulent transfer of latent and sensible heat remains largely unexplored. This is probably a reflection of the difficulties encountered in measuring turbulent exchange, and especially the problems posed by the complexity of the city-atmosphere interface. This study provides direct observational evidence of the nature of the sensible heat flux over a large, temperate-latitude city in summer.

Indirect approaches to the measurement of the turbulent sensible heat flux $\left(Q_{H}\right)$ rely on a number of restricting assumptions regarding the state of the surface or the atmosphere. Most of these assumptions cannot be fulfilled in the city. Direct measurement via the eddy correlation technique is much more attractive, but often very much more expensive and technically complex. Previous experience with the relatively simple yaw sphere-thermometer (YST) eddy correlation system suggested that it may overcome these difficulties (Yap et al., 1974; Yap and Oke, 1974) and prove to be suitable in the urban context.

\section{The urban site}

Observations were conducted above the flat-top roof of a four-story building (the Vancouver School

\footnotetext{
${ }^{1}$ Atmospheric Environment Service, Downsview, Ontario.

Department of Geography, University of British Columbia, Vancouver, B. C.
}

Board building, hereinafter termed VSB). The site is located in a mixed commercial and medium-rise residential district in the central part of Vancouver. A site plan of the VSB building and the surrounding land uses within $2 \mathrm{~km}$ is given in Fig. 1. The area has a 1:80 slope down to False Creek in the north. Airflow from this direction could not always be avoided, but measurements close to the roof should not be affected. The minimum fetch to this non-urban surface is about $1.5 \mathrm{~km}$.

The buildings within the $2 \mathrm{~km}$ radius were fairly uniform in height (10-13 m), roof type (flat, gravel on tar) and density (70-80\% of each block being occupied by buildings). Some height variations occurred to the east and some density differences $1-2 \mathrm{~km}$ to the south and northeast. A survey of the whole circle shown in Fig. 1 revealed that approximately $70 \%$ of the total horizontal surface area was impervious. Closer to the VSB site about $80 \%$ was impervious.

A plan view of the VSB roof top is shown in Fig. 2. The roof surface was tarred with an almost complete cover of gravel chips. Radiation measurements showed the roof shortwave albedo to be 0.09 and the longwave emissivity to be 0.92 . The rest of the building was constructed of brick and concrete. There were no major ventilation outlets at roof level. The incineration outlet was $11 \mathrm{~m}$ above the main experimental roof and only operated for short periods.

Instrument locations are identified on Fig. 2. Sensible heat flux density was measured by the YST system, details of which are available in Tanner and Thurtell (1970) and Yap et al. (1974). Observations were conducted $1.2,1.5,2,4$ and $20 \mathrm{~m}$ above the main roof. A second YST system was added for the spatial sampling experiment. Net radiation $\left(Q^{*}\right)$ was 


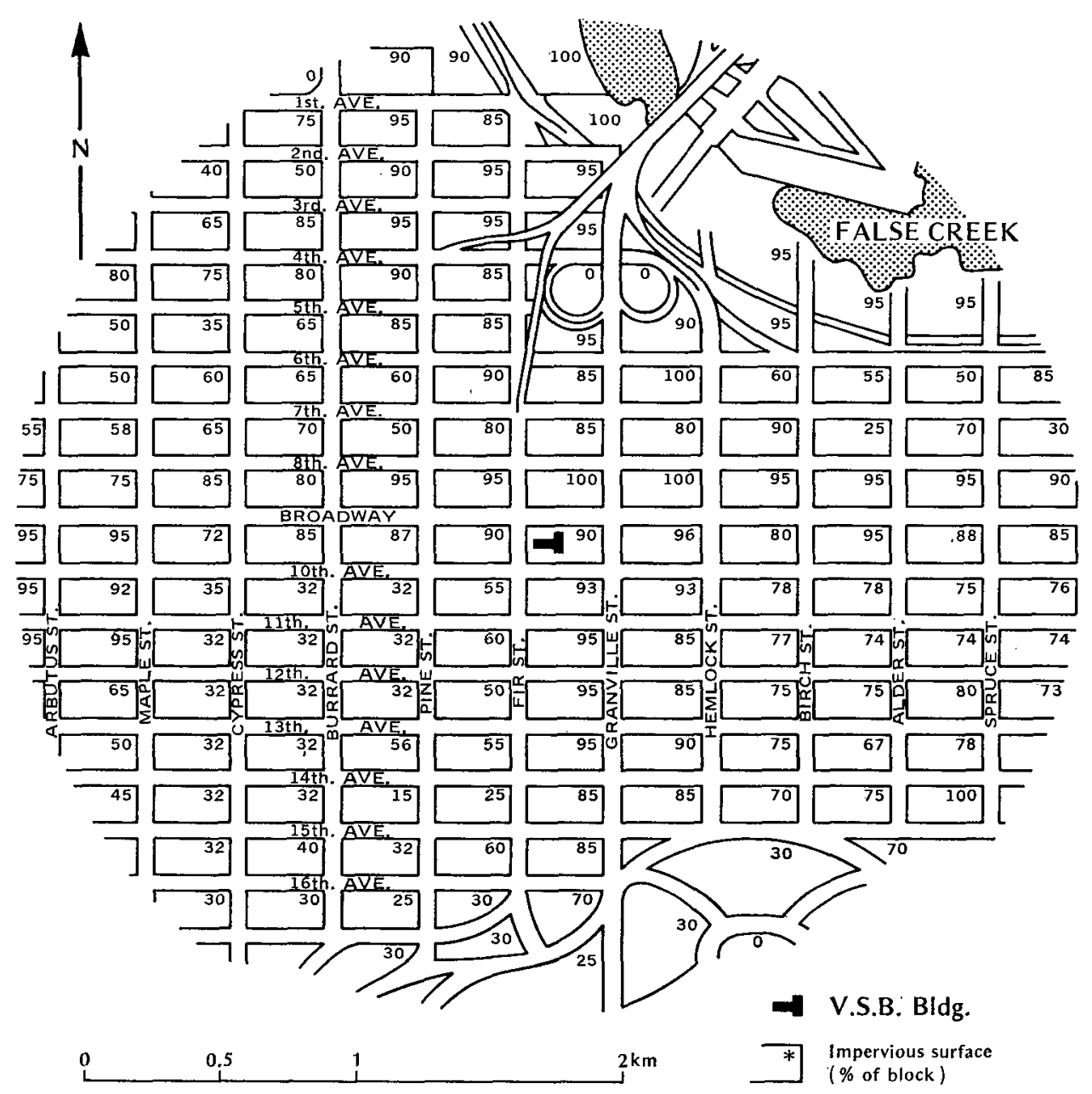

FIG. 1. Site plan of the urban area (Vancouver School Board building and its immediate environs).

measured using a net radiometer (Swissteco Pty, Ltd., Model S-1) at $20 \mathrm{~m}$, and heat storage $\left(Q_{G}\right)$ was measured by a heat flux plate (Middleton and Co.) embedded $\sim 0.5 \mathrm{~cm}$ in the roof. A similar plate was placed in a tarmacadam block. Values of $Q_{G}$ presented here are not corrected for flux divergence in the overlying surface layer and are therefore underestimates. The radiometer and roof flux plate were continuously recorded on volt-time integrators (Lintronic Ltd.).

\section{Airflow considerations}

The airflow around buildings in an urban area is very complex. For an isolated building the typical flow pattern is illustrated in Fig. 3. Although this ignores the mutual interference from surrounding structures (e.g., Smith, 1972) it provides some insight into the problems to be anticipated in conducting measurements above a roof. In particular, we might expect differences between data gathered in the near-roof turbulent zone as compared with those from above the surface of separation.
Simple investigation of the mean vertical velocity field $(\bar{w})$ over the roof was conducted with Gill propellor anemometers (R. M. Young Co.) mounted in the vertical. Near the surface $\bar{w}$ was less than $0.1 \mathrm{~m}$ $\sec ^{-1}$ with a predilection for negative values (i.e., downdrafts). This is probably within the resolution capacity of the propellor. At $20 \mathrm{~m}$ values were still small but favored positive values (updrafts). Wind direction measurements from the YST systems gave marked variability at $1.2 \mathrm{~m}$, but at $4 \mathrm{~m}$ the direction was more constant and consistent with the $20 \mathrm{~m}$ level. From these observations we conclude that measurements up to about $2 \mathrm{~m}$ are within the turbulent boundary layer of the roof. Measurements at $4 \mathrm{~m}$ and higher are above the local boundary layer and represent areal urban heat fluxes.

\section{Time sampling}

For a given site and height the choice of sample length necessary to achieve stable average heat fluxes via eddy correlation is determined by the frequency 


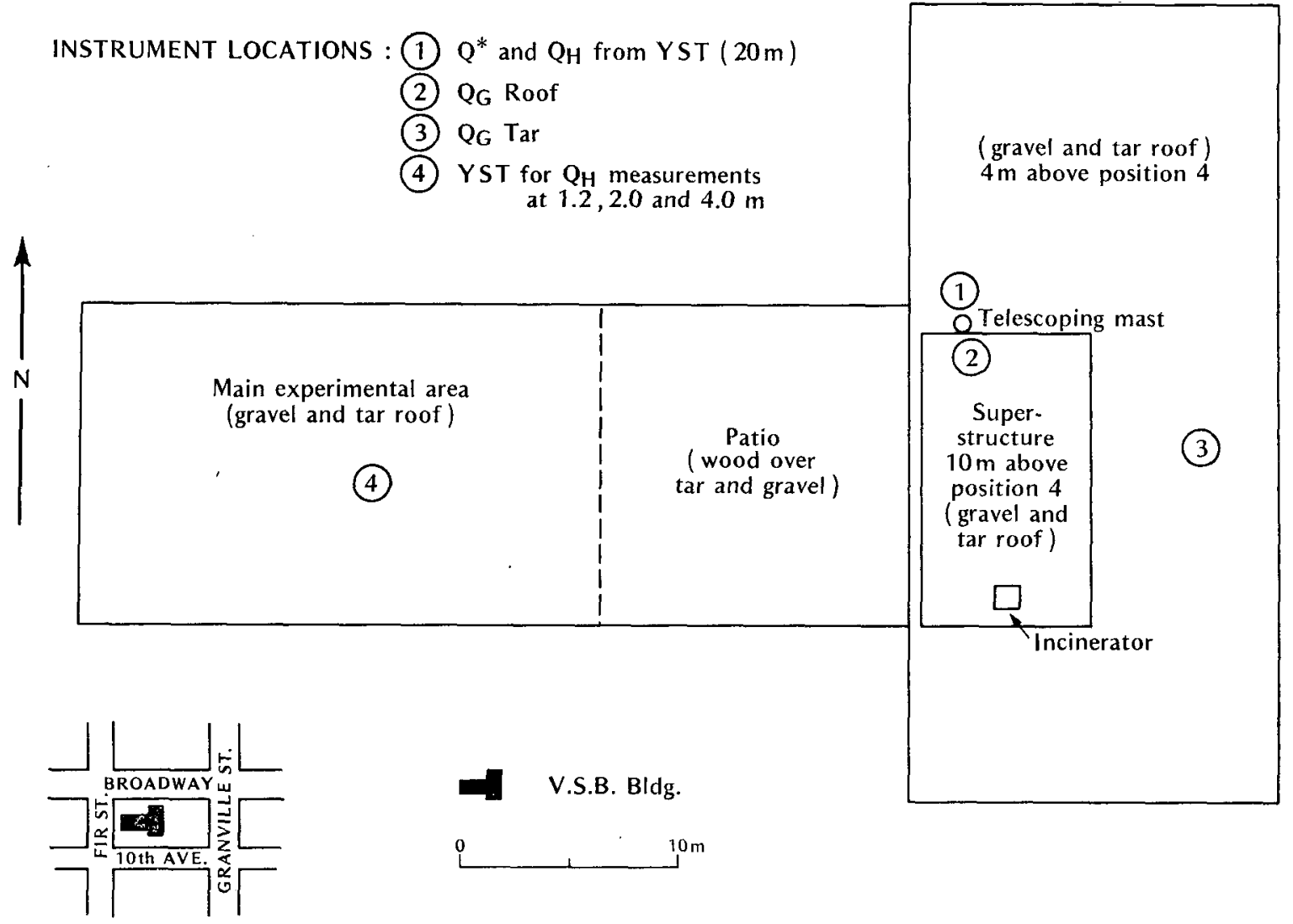

Fig. 2. The Vancouver School Board building (plan view).

distribution of the $w T$ cospectral components. The case of uniform rural sites is fairly well understood from the work of Businger et al. (1967) and Chou (1966). They find significant contributions to the sensible Theat flux cospectrum down to $0.003 \mathrm{~Hz}$, thus

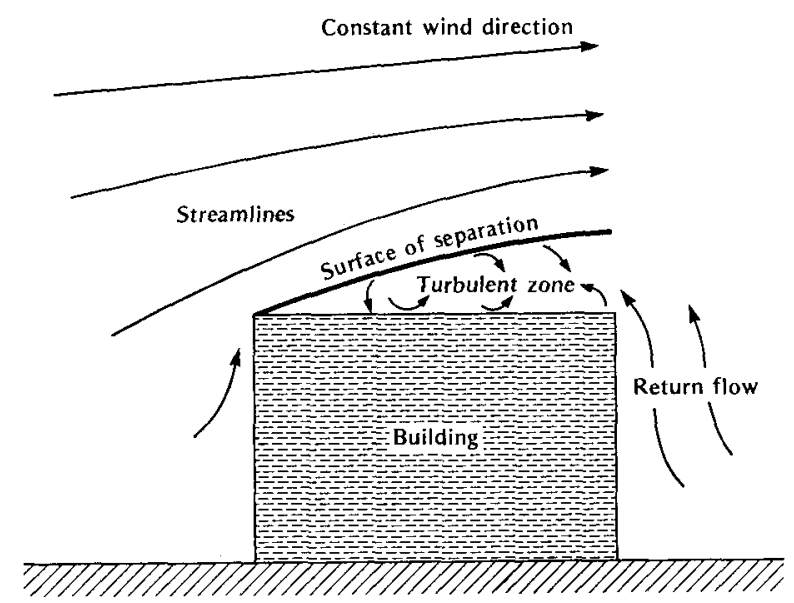

FIG. 3. Schematic of the airflow and local boundary development above a building for a constant angle of attack of the wind flow (after Halitsky, 1962). requiring sample intervals $>20 \mathrm{~min}$; hence, $30 \mathrm{~min}$ is commonly used.

In contrast, there is no experimental evidence to identify the significant frequency domain for urban sensible heat fluxes. Steenbergen (1971) indicates that in comparison to the rural situation there is a shift of energy in the $r$ spectrum toward lower frequencies. The urban $T$ spectrum is not known but it also may move to lower frequencies. Consequently, the need for sample intervals $>30$ min might be anticipated in the city.

The output from the YST system was in continuous analog form. Hence, by integrating over different time intervals the effect of sample length was investigated. Figs. 4 and 5 illustrate the effects of different sample intervals applied to data measured at 1.2 and $4 \mathrm{~m}$ over the VSB roof. With a sample interval of $30 \mathrm{~min}$ it was common to find $Q_{H}$ fluctuations which were not obviously related to $Q^{*}$. These fluctuations could be a result of the scale of turbulence found over the urban area, or be due to poor sampling. There were occasions, however, when 30-min averages appeared adequate. Using a 1-hr interval reduced many of the fluctuations (Fig. 4) but not on all occasions (Fig. 5). The very large oscilla- 


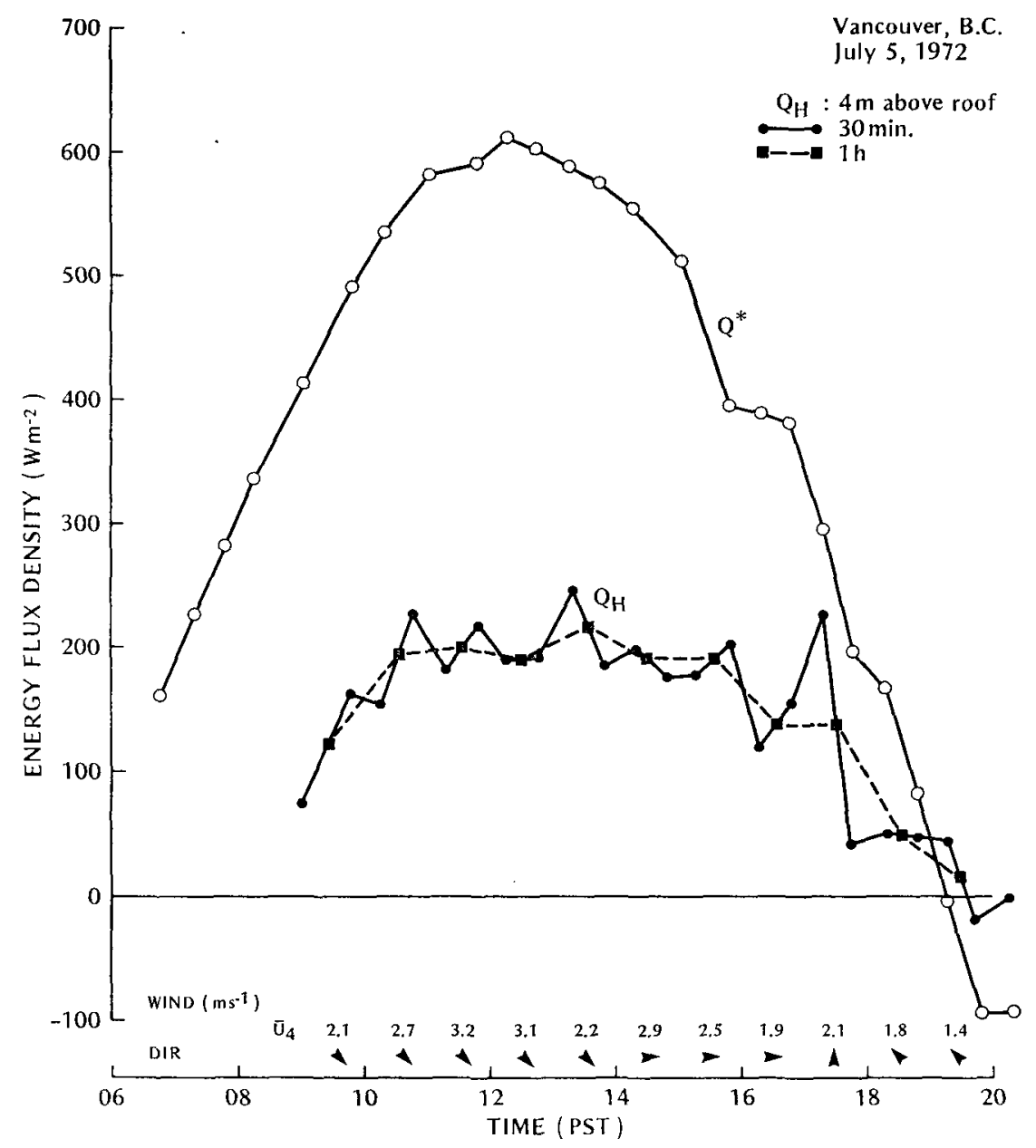

FIG. 4. Urban sensible heat fluxes for 30 -min and 1 -hr averaging periods and net radiation for 5 July 1972.

tions unrelated to $Q^{*}$ around midday were not uncommon. We can only speculate that their cause lies in a convective phenomenon perhaps related to interaction with circulation in and above adjacent street canyons. In this period (1000-1400 PST) 2-hr averages would smooth the fluctuations, and give a correspondence between $Q_{H}$ and $Q^{*}$, but there is a danger that non-steady-state conditions may occur.

In review, it appears that a single optimum urban sampling interval may not be appropriate. It was often noted that 30 min was satisfactory with low radiation inputs, the heat fluxes being stable and reflecting the $Q^{*}$ field. Thus, it may be that with reduced thermal convection the lower frequency contributions become less important. Although not totally satisfactory, sampling intervals of $30 \mathrm{~min}$ or $1 \mathrm{hr}$ were selectively employed.

\section{Space sampling}

Knowledge of the horizontal and vertical variability of the sensible heat flux is necessary in order to assess the value of point measurements. Limited experiments to test this variability were conducted over the VSB roof using two XST systems whose calibrations were found to be within 5\% (Yap and Oke, 1974).

Horizontal variability was checked with both YST systems at $1.5 \mathrm{~m}$ (i.e., within the roof turbulent zone) and separated by 2.5 and $7 \mathrm{~m}$ (Fig. 6). For both separations the overall trends were similar but individual hourly values were variable. Cumulative heat flux totals expressed as a ratio $Q_{H} \mathrm{YsT}_{1} / Q_{H} \mathrm{YsT}_{2}$ suggest a variation of approximately $20 \%$ (Table 1 ). When a vertical separation of $0.8 \mathrm{~m}$ was used, between 1.2 and $2 \mathrm{~m}$ (i.e., both within the roof turbulent zone), the trends were again similar and the variation within $20 \%$ (Fig. $7 \mathrm{a}$ and Table 1 ).

The use of a vertical separation of $2.8 \mathrm{~m}$, between 1.2 and $4 \mathrm{~m}$, gave greater variability, especially on 1 September when the radiant input was stronger. This is interpreted to mean that the measurement levels were on either side of the boundary layer surface of separation (Fig. 3) and hence not deriving their 


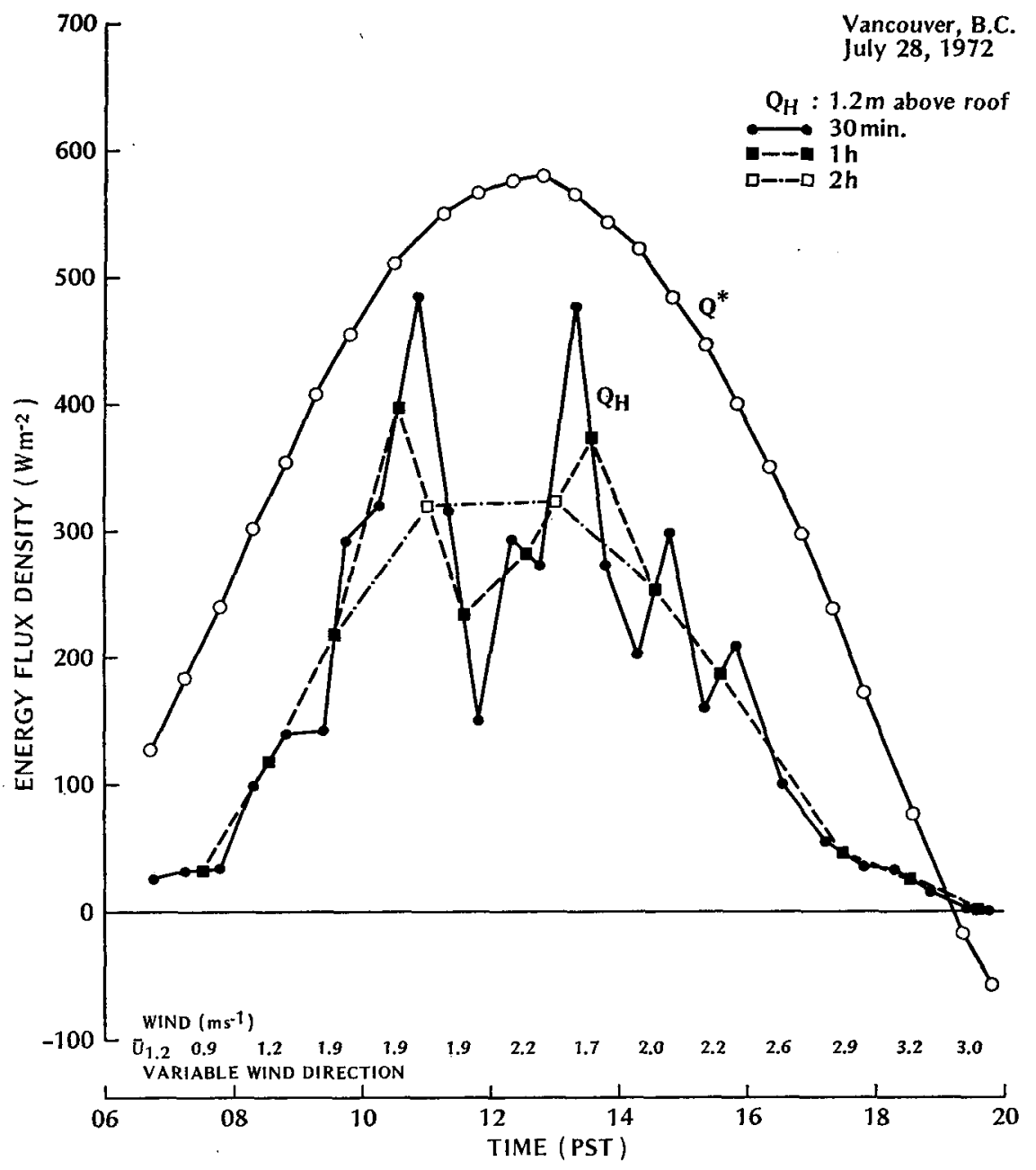

FIG. 5. Urban sensible heat fluxes for 30-min, 1- and 2-hr averaging periods and net radiation for 28 July 1972.

fluxes from the same active surface. No measurements were made to test vertical variability for heights $>4 \mathrm{~m}$.

We conclude that a $20 \%$ variability may be expected for measurements within the roof boundary layer.

\section{Diurnal pattern of urban sensible heat fluxes}

Urban sensible heat fluxes were observed on 27 days in the period 5 July to 1 September, 1972. On 10 of these days data extend over the complete 24 -hr period. From these results (Figs. 4, 5 and 8-10) features of the diurnal pattern of $Q_{I I}$ became evident.

During the daytime $Q_{H}$ was directed upward, away from the urban surface. On clear days the $Q_{H}$ and $Q^{*}$ fluxes were in phase with each other, both reaching a peak at about midday. Except for the fluctuations noted in Section 4 the $Q_{H}$ and $Q^{*}$ fluxes were consistently linked, and during the main daylight hours $Q_{H}$ never exceeded $Q^{*}$. This is important since the
$Q_{H}$ and $Q^{*}$ measurements are totally independent of each other (unlike Bowen ratio estimates, for example). These daytime features were found on all observation days and at all measurement heights. The absolute magnitude of $Q_{I I}$ decreased from 1.2 to $4 \mathrm{~m}$ above the roof. This is anticipated since the $1.2 \mathrm{~m}$ level represents the roof flux, whereas the $4 \mathrm{~m}$ level represents a larger space average flux from the roof and surrounding areas which will include a larger proportion of evaporating surfaces, and shadow areas.

On about two-thirds of the days the late afternoon, early evening $Q_{H} / Q^{*}$ ratios remained surprisingly high (e.g., Figs. 4, 8 and 9). The cause of this behavior could not be isolated, but the following explanation is offered. During the day large amounts of heat are likely to be stored in the urban fabric, not only in the roof tops but also in building walls, streets, etc. The release of this heat is likely to occur somewhat earlier than sunset. This is due to the geometric configuration of the building elements, which at high zenith angles 


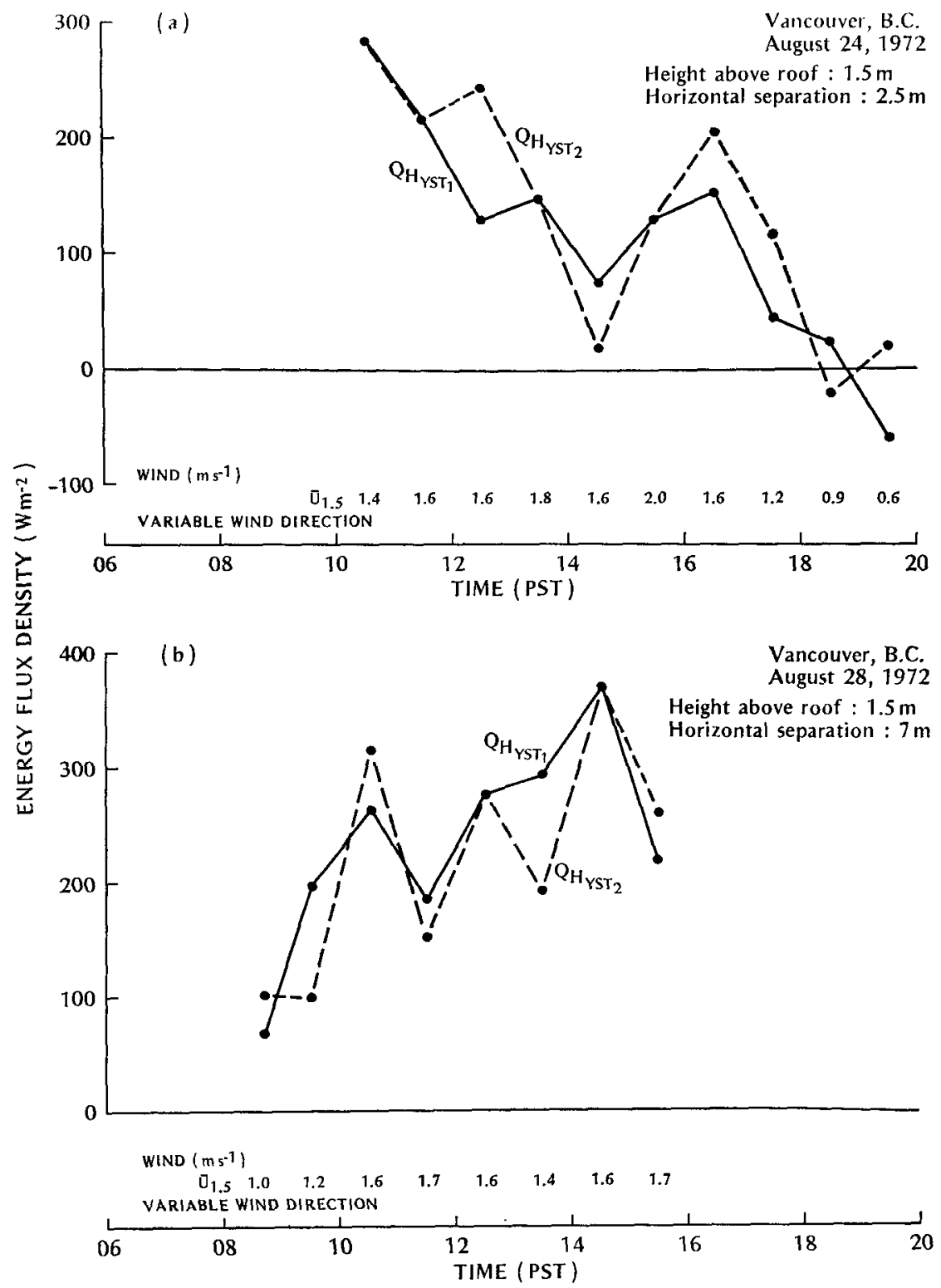

FIG. 6. Horizontal spatial variation of the urban sensible heat fluxes.

cause extensive shadow areas to be quickly generated. The consequent removal of the direct beam radiation input causes surface cooling, and an enhanced heat flux directed upward. A scaled-down example of this effect is seen in Fig. 11. The flow of heat into the roof ( $Q_{G \text { ROOF}}$ ) shows a normal course through the day. The flow in the tar block $\left(Q_{G \text { TAR }}\right)$ parallels $Q_{G \text { RooF }}$ at a slightly higher rate until just before 1600 PST when, unlike the roof plate, it was cast into shadow by the superstructure on the roof (Fig. 2). Almost immediately $Q_{G}$ TAR reversed its direction of flow. This behavior of the storage term would be likely to enhance $Q_{H}$ in the urban area. By the same token early morning storage input might be retarded in the city relative to $Q^{*}$, possibly causing a lag in $Q_{H}$.
TABLE 1. Comparison of daytime cumulative sensible heat flux densities from the yaw sphere-thermometer systems (YST 1 and $\mathrm{YST}_{2}$ ) above the urban roof.

\begin{tabular}{|c|c|c|c|}
\hline $\begin{array}{l}\text { Date } \\
(1972)\end{array}$ & $\begin{array}{l}\text { Dura- } \\
\text { tion } \\
(\mathrm{min})\end{array}$ & $\frac{Q_{H} \mathbf{Y} \$ \mathbf{T}_{1}}{Q_{H} \mathbf{Y s T}_{2}}$ & Remarks \\
\hline 24 August & 584 & 0.79 & $\begin{array}{c}\text { horizontal separation } 2.5 \mathrm{~m} \text { at } \\
1.5 \mathrm{~m} \text { level above r oof top }\end{array}$ \\
\hline $\begin{array}{l}28 \text { August } \\
29 \text { August } \\
25 \text { August }\end{array}$ & $\begin{array}{l}420 \\
332 \\
682\end{array}$ & $\begin{array}{l}1.09 \\
0.98 \\
0.88\end{array}$ & $\begin{array}{l}\text { horizontal separation } 7.0 \mathrm{~m} \text { at } \\
1.5 \mathrm{~m} \text { level above roof top } \\
\text { * vertical separation } 0.8 \mathrm{~m} \text {, at } \\
1.2 \text { and } 2.0 \mathrm{~m} \text { levels above } \\
\text { roof top }\end{array}$ \\
\hline $\begin{array}{l}30 \text { August } \\
1 \text { September }\end{array}$ & $\begin{array}{l}525 \\
426\end{array}$ & $\begin{array}{l}0.88 \\
1.48\end{array}$ & $\begin{array}{l}\text { *vertical separation } 2.8 \mathrm{~m} \text {, at } \\
1.2 \text { and } 4.0 \mathrm{~m} \text { levels above } \\
\text { roof top }\end{array}$ \\
\hline
\end{tabular}

* $\mathrm{YST}_{1}$ at the $1.2 \mathrm{~m}$ level and $\mathrm{YST}_{2}$ at the 2.0 and $4.0 \mathrm{~m}$ levels. 

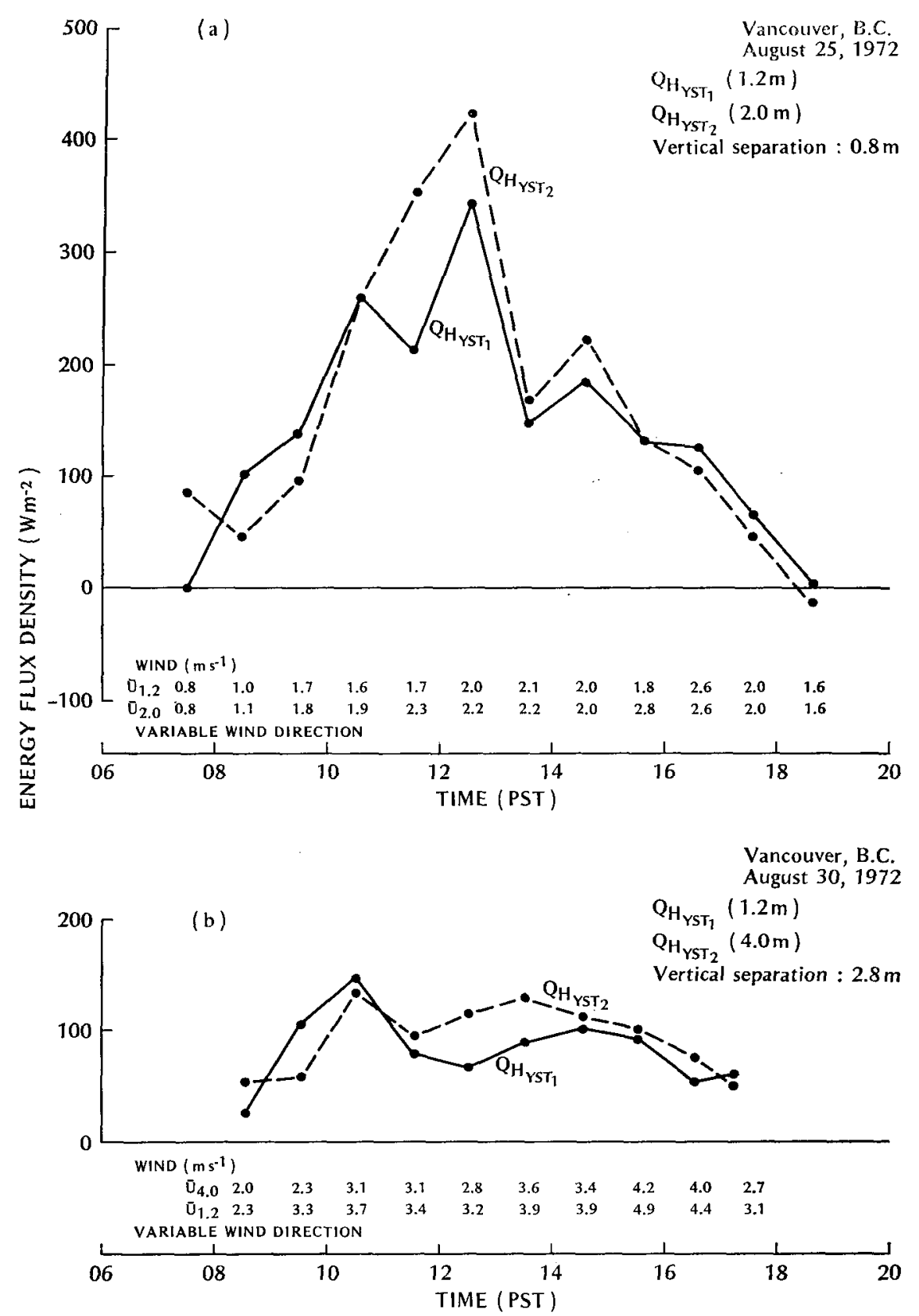

FIG. 7. Vertical spatial variation of the urban sensible heat fluxes.

The evidence for this is less obvious. Additional explanations for the relatively high afternoon $Q_{H}$ values might include return flow from the heated canyons, and/or an increased urban resistance to vapor flow.

The nighttime $Q_{H}$ pattern is unique to urban areas and not previously reported. Quite unlike rural areas $Q_{H}$ was noted to remain directed away from the surface through the night (see Figs. 8-10). Confidence in the absolute magnitude of the nocturnal values is reduced since they are often at times of low wind speeds (the YST theory of operation is best suited to wind speeds $>0.6 \mathrm{~m} \mathrm{sec}^{-1}$ ), but the sign of the flux was very consistent. At $1.2 \mathrm{~m}$ this behavior was dominant, at 4 and $20 \mathrm{~m}$ the direction of flow was more variable, but upward flow was common. This feature seems consistent with the observation that urban temperature inversions are rare (Munn and Stewart, 1967). Taken in conjunction with the high $Q_{H}$ flow in late afternoon, this lack of reversal in the nighttime / sensible heating must be considered to be a source term in the development of the urban heat island. It is also noted that the heat island is observed 


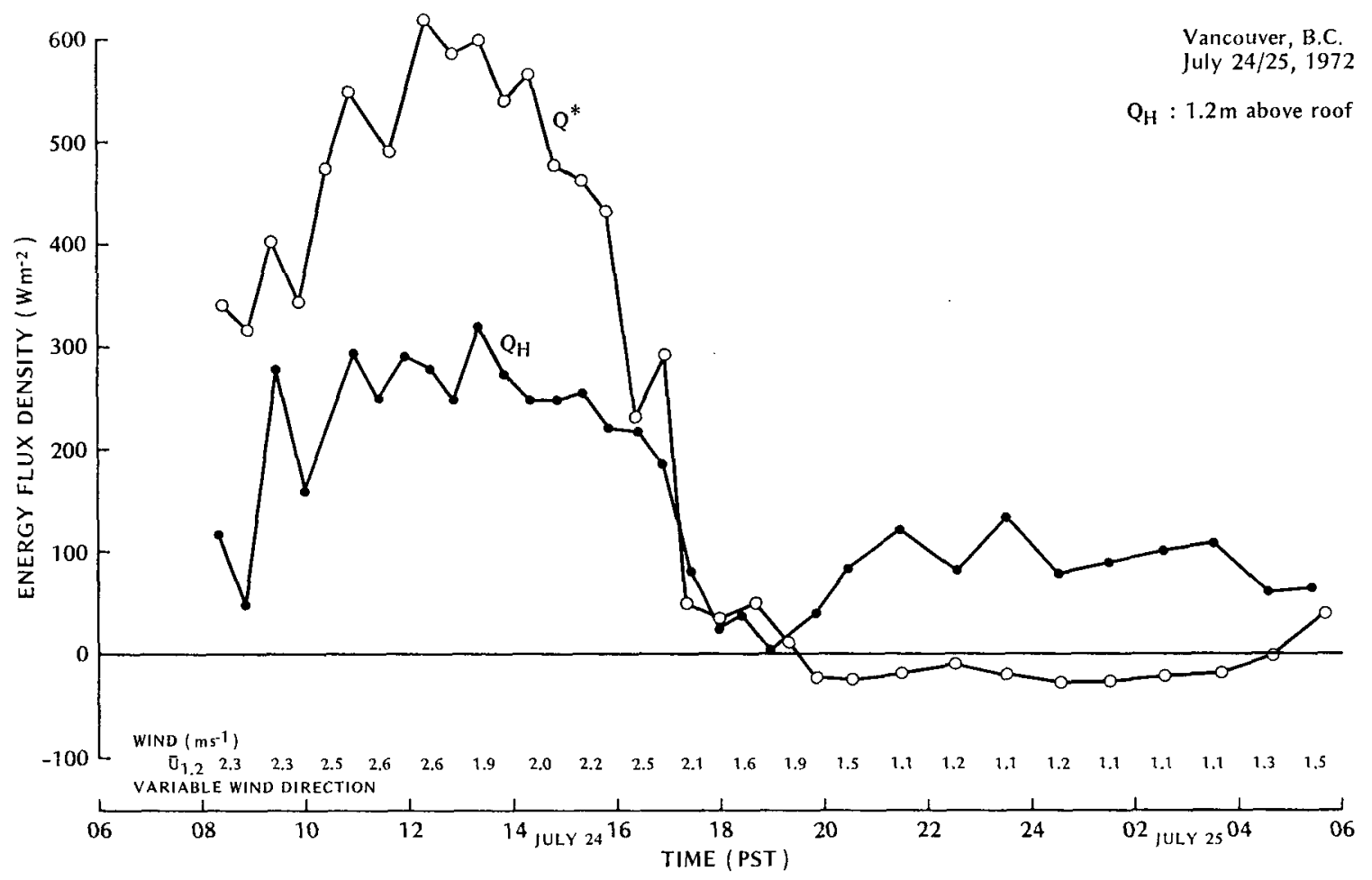

FIG. 8. Diurnal variation of the urban net radiation, and the sensible heat flux at $1.2 \mathrm{~m}$ above roof for $24 / 25 \mathrm{July} 1972$.

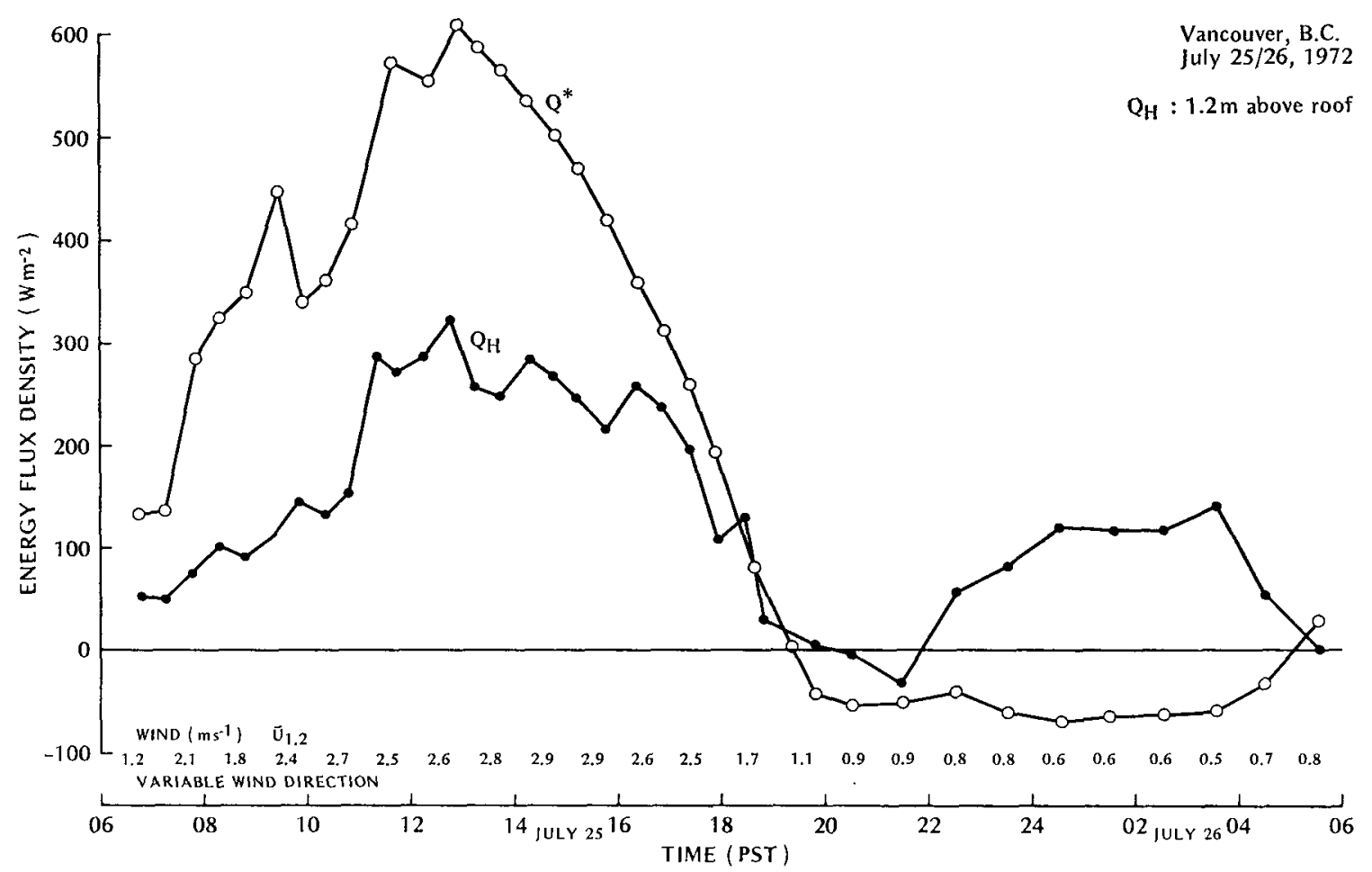

FIG. 9. As in Fig. 8 except for 25/26 July. 


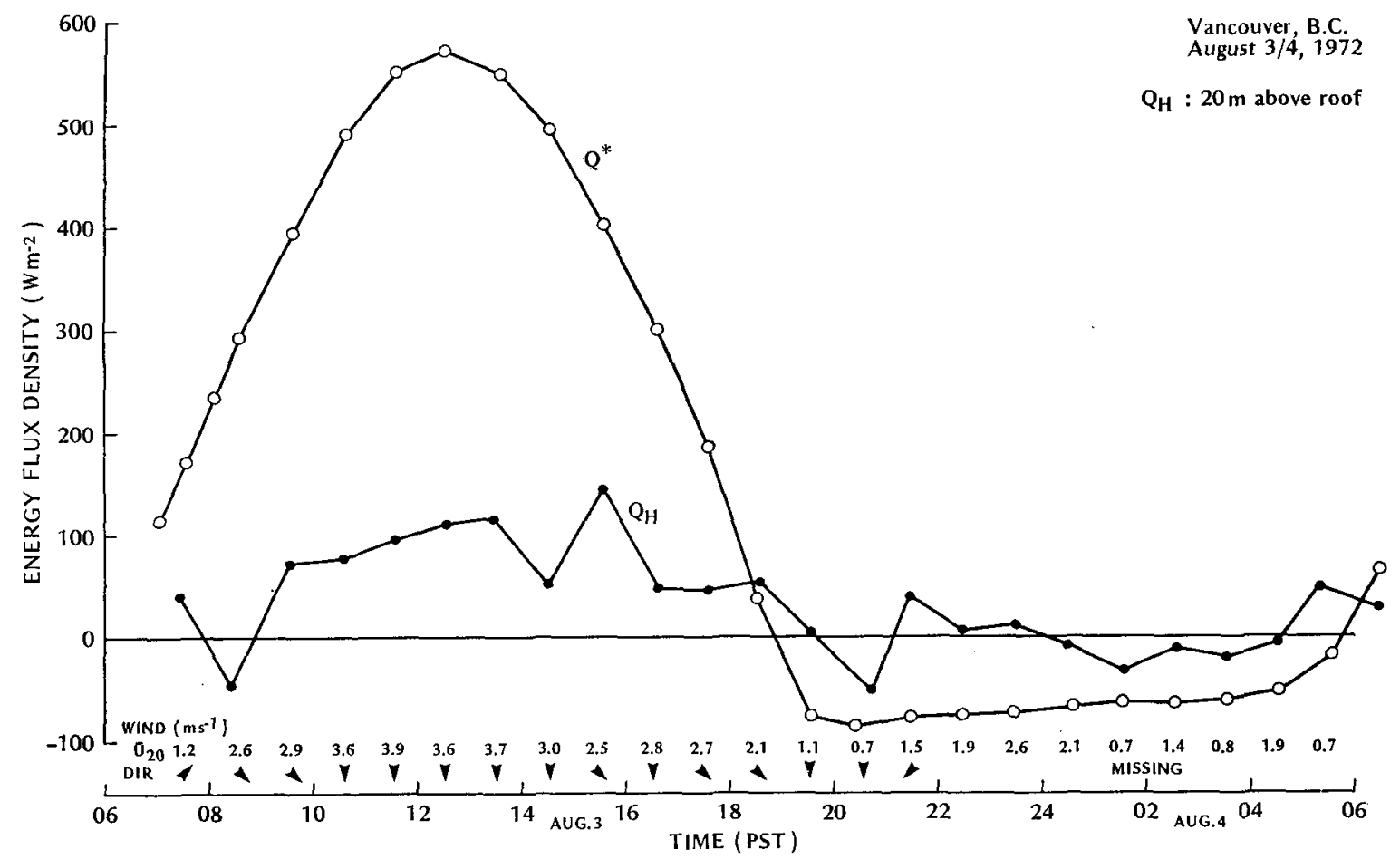

Frc. 10. Diurnal variation of the urban net radiation, and the sensible heat flux at $20 \mathrm{~m}$ above roof for $3 / 4$ August 1972 .

to begin a rapid growth in this same period just before sunset (Oke and East, 1971; Hage, 1972; Oke and Maxwell, 1974).

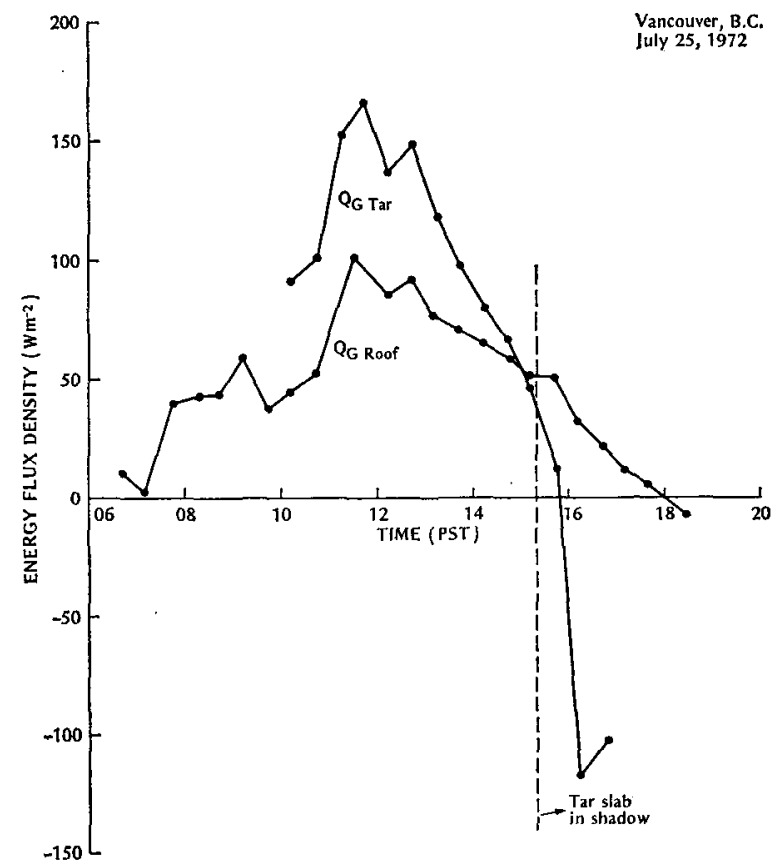

FIG. 11. Effect of shadow on the diurnal behavior of urban heat storage.
At night $Q_{H}$ was noted to decrease with height. With light winds it is unlikely that this is the result of boundary layer development; hence, it may be interpreted as evidence of sensible heat flux convergence in the lower urban atmosphere. Fuggle (1971) concluded that this must be so from studying radiative flux divergence over a building at night.

Fig. 12 indicates the influence of surface moisture in the partitioning of sensible and latent heat in an urban area. Using the measurements of $Q^{*}, Q_{H}$ and

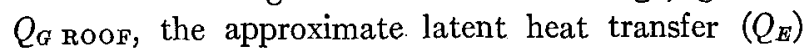
was obtained as the residual from the simple heat balance equation. Prior to 7 July 1972 (Fig. 12a) there were 10 days without precipitation, and the balance shows $Q_{H}$ to be the main urban energy sink. Following this, a record $8 \mathrm{~cm}$ of rain fell, ceasing on 12 July (Schaefer, 1973). On 13 July (Fig. 12b) roof tops were saturated and $Q_{H}$ dropped very markedly suggesting that latent heat transfer was dominant. In the following drying period $Q_{H}$ regained its former position in the balance so that by 17 July (Fig. 12c) conditions were approaching those prior to the rainfall. The residual term $\left(\sim Q_{E}\right)$ was significant, suggesting that the urban surface is not "dry." The time response of the city following this wetting suggests that it requires a period of at least 5 days to recover its original moisture state. 


\section{Conclusion}

This study has considered some of the problems involved in implementing the eddy correlation approach in the case of the city. Despite obvious limitations the approach appears to have worked well in the case of sensible heat flux measurements with a
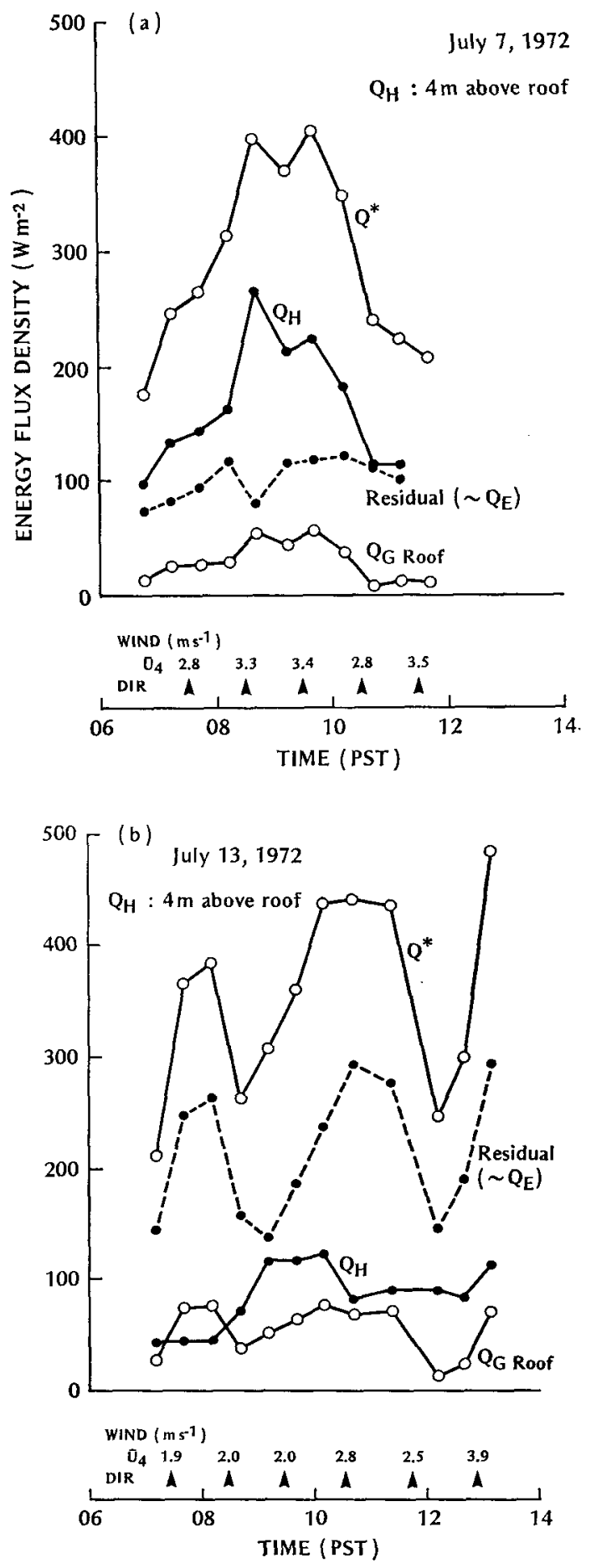

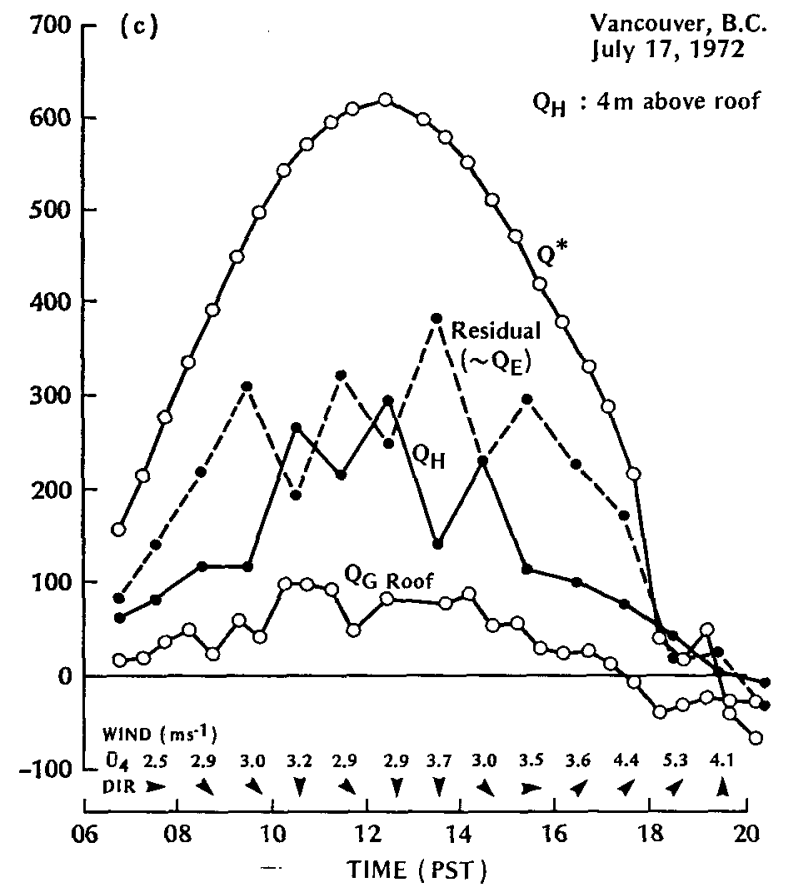

F1G. 12. Urban energy balances: (a) 7 July, 1972 with dry conditions; (b) 13 July, 1972 following wet period; and (c) 17 July, 1972, 5 days after wet period ended.

yaw sphere-thermometer system over a building in central Vancouver. Measured values appear to be stable and to reveal a number of uniquely urban features. These include a lag in the decline of $Q_{H}$ in the late afternoon, and failure of $Q_{H}$ to reverse its direction of flow at night. These first results of turbulent heat transfer in the city raise almost as many questions as they answer. In particular, they point to the need for information on the significant frequency domain for urban sensible heat fluxes. Similarly, the heat storage and release by building materials and different building configurations (including the effects of shadows) deserves more attention. Finally, there is a need for research which will help us to understand the coupling between the energetic process at street level (and the urban canyons) and those at roof level and above.

Acknowledgments. This research was conducted under grants from the National Research Council of Canada and the Canadian Department of the Environment (Atmospheric Environment Service). Thanks are also extended to the Vancouver School Board for use of their building and facilities.

\section{REFERENCES}

Businger, J. A., M. Miyake, A. J. Dyer and E. F. Bradley, 1967 : On the direct determination of the turbulent heat flux near the ground. J. Appl. Meteor., 6, 1025-1032. 
Chou, M. Y., 1966: The optimum averaging periods for measurements of meteorological fields. Izv. Aimos. Oceanic Phys., 2, 293-295.

Fuggle, R. F., 1971 : Nocturnal atmospheric infra-red radiation in Montréal. Ph.D. thesis, McGill University, 237 pp.

Hage, K. D., 1972: Nocturnal temperatures in Edmonton, Alberta. J. Appl. Meteor., 11, 123-129.

Halitsky, J., 1962: Diffusion of vented gas around buildings. J. Air Poll. Control Assoc., 12, 74-80.

Munn, R. E., and I. M. Stewart, 1967 : The use of meteorological towers in urban air pollution programs. J. Air Poll. Control Assoc., 17, 98-101.

Oke, T. R., and C. East, 1971: The urban boundary layer in Montréal. Boundary Layer Meteor., 1, 411-437.

- - and G. B. Maxwell, 1974: Urban heat island dynamics in Montréal and Vancouver. Atmos. Environ. (in press).

Schaefer, D. G., 1973: A record breaking summer rainstorm over the Lower Fraser Valley. Canada Atmos. Environ. Service, TEC 787, $29 \mathrm{pp}$.

Smith, C. V., 1972: The aerodynamics of buildings. Some Environmental Problems of Livestock Housing, WMO Tech. Note No. $122,15-26$.

Steenbergen, J. D., 1971: Comparison of urban and rural turbulence statistics at Edmonton, Alberta. M.Sc. thesis, University of Alberta, $86 \mathrm{pp}$.

Tanner, C. B., and G. W. Thurtell, 1970: Sensible heat flux measurements with a yaw sphere and thermometer. Boundary Layer Meteor., 1, 195-200.

Yap, D., and T. R. Oke, 1974: Eddy correlation measurements of sensible heat fluxes over a grass surface. Boundary Layer Meteor. (in press).

- T. A. Black and T. R. Oke, 1974: Calibration and tests of a yaw sphere-thermometer system for sensible heat flux measurements. J. Appl. Meteor., 13, 40-45. 